Data Monitoring in Clinical Trials 
David L. DeMets

Curt D. Furberg

Lawrence M. Friedman

Editors

\section{Data Monitoring in Clinical Trials}

A Case Studies Approach

With 40 Illustrations

照 Springer 
David L. DeMets

Department of Biostatistics and Medical Informatics

University of Wisconsin Medical School

Madison, WI 53972-4675

USA

Lawrence M. Friedman

Bethesda, MD

USA
Curt D. Furberg

Department of Public Health Sciences

Wake Forest University School

of Medicine

Winston-Salem, NC 27157

USA

Library of Congress Control Number:

ISBN-10: 0-387-20330-3

Printed on acid-free paper.

ISBN-13: 978-0387-20330-0

(C) 2006 Springer Science+Business Media, Inc.

All rights reserved. This work may not be translated or copied in whole or in part without the written permission of the publisher (Springer Science+Business Media, Inc., 233 Spring Street, New York, NY 10013, USA), except for brief excerpts in connection with reviews or scholarly analysis. Use in connection with any form of information storage and retrieval, electronic adaptation, computer software, or by similar or dissimilar methodology now known or hereafter developed is forbidden.

The use in this publication of trade names, trademarks, service marks, and similar terms, even if they are not identified as such, is not to be taken as an expression of opinion as to whether or not they are subject to proprietary rights.

Printed in the United States of America.

(MP)

987654321

springeronline.com 


\section{Preface}

Monitoring of clinical trials for early evidence of benefit and harm has gotten considerable attention. ${ }^{1}$ More formal guidelines and requirements ${ }^{2-4}$ have evolved in recent years, but in fact monitoring of trials is a practice that has been going on for almost four decades. ${ }^{5}$ For trials that involved conditions or interventions with serious risks, such as mortality or major morbidity, the tradition and policy has been to have an independent monitoring committee to review accumulating data for evidence of harm or convincing benefit that would require modifying or terminating a trial early. During the past four decades, many trials have had monitoring committees to assume this responsibility. With the new emphasis on monitoring, this type of activity is increasing dramatically as the number of clinical trials being conducted to evaluate new interventions for patients or participants with serious risk or serious outcomes also increases. For example, policies of the National Institutes of Health (NIH) in the United States (US) call for monitoring committees for all phase III trials. ${ }^{2}$ Guidelines of the US Food and Drug Administration suggest such committees for trials of high-risk interventions or patients at high risk. ${ }^{3}$

As the number of monitoring committees increases, the challenge exists to pass along the experiences and best practices of the monitoring process to colleagues who are assuming this responsibility for the first time. Textbooks such as the one by Ellenberg, Fleming, and DeMets ${ }^{6}$ provide many of the basic principles for monitoring committees. Other texts such as those by Friedman, Furberg, and DeMets; $;^{7}$ Meinert $;^{8}$ Pocock; ${ }^{9}$ Jennison and Turnbull, ${ }^{10}$ and Piantidosi ${ }^{11}$ provide statistical fundamentals and methods for the design, monitoring, and analysis of clinical trials. This text is intended to complement those texts by providing a collection of examples or case studies of monitoring experiences from a variety of trials across different disease disciplines. Each case study will describe the background of the individual trial, summarize the overall results, review the critical issues that emerged in the monitoring of the trial, and finally reflect on the lessons learned from that trial. All of the examples presented share the complexity of the process of monitoring and the lesson that no single rule or algorithm can replace the wisdom and judgment of a monitoring committee. Through these examples, we hope to share the experience of these past committees and pass along some of their sometimes hard-earned wisdom.

Selection of the case studies was largely based on the collective experiences of the editors and their interactions with colleagues involved with clin- 
ical trials. Many of the 29 examples are from the field of cardiology, where the practice of monitoring committees was established early. However, there are examples from other disciplines. Regardless of the disease, many of the lessons learned and practices are useful for any trial. Individual colleagues were invited to present the monitoring experience of a trial they were involved with as they saw it and experienced it. Their presentations and discussions do not necessarily represent the official view of either the trial sponsor, the trial investigators, or the trial monitoring committee. We have tried to get representation from each of these constituencies on many of the trials when possible.

For most of the past four decades, the existence and practice of monitoring committees has not been widely recognized or understood. Our belief is that clinical research will benefit with better understanding of the process by both the research community and the interested public. The intended audience for this book are those who are planning to serve on a monitoring committee or are already on one and wish to gain further insight into the monitoring and decision-making process. We also believe that these examples will be useful to investigators as they design their trials and propose monitoring procedures; to sponsors, who typically receive monitoring committee recommendations, and to regulatory agencies, who often must review the results of trials that have been monitored by a committee. In addition, Institutional Review Boards may benefit from these case studies since they ultimately have responsibility for protecting participants at the local level but must rely on the monitoring committee process for most multicenter trials and increasingly for institutional trials. Journal editors, sciences writers, and practicing physicians may also find these case studies instructive.

Over the past four decades, many individuals have served on monitoring committees and participated in the monitoring of many challenging studies. We wish to thank all of those individuals who have contributed directly or indirectly to the practice of monitoring and from whose experience we all have benefitted. We have listed in Appendix 1 the individuals who have served on the committees for the trials presented as case studies in this book and wish to thank them in particular.

\section{ACKNOWLEDGMENTS}

We also want to thank the many contributors to the drafting of these case studies. We have listed them in the section which follows. They contributed their experiences because of their commitment to clinical trials, the monitoring process, and to teaching the next generation of clinical trial researchers about the important process of monitoring trials for early evi- 
dence of benefit or harm. We are grateful that they accepted our invitation and persevered through the drafts and editing process.

We would also like to acknowledge the substantial contributions by Ms. Suzanne Parman for her editorial and logistical support. Without her dedication this text could not have been completed in a timely fashion.

David L. DeMets

Curt D. Furberg

Lawrence M. Friedman

\section{REFERENCES}

1. Shalala D: Protecting research subjects-what must be done. 2000. N Engl J Med 343: 808-810.

2. National Institutes of Health. 2000. Further Guidance on a Data and Safety Monitoring for Phase I and Phase II Trials, NIH Guide, June 5, 2000. http://grants.nih.gov/grants/guide/ notice-files/NOT-OD-00-038.html

3. US Food and Drug Administration. 2001. Draft Guidance for Clinical Trial sponsors on the establishment and operation of Clinical Trial Data Monitoring Committees. Rockville, MD: FDA. http://www.fda.gov/cber/gdlns/clindatmon.htm

4. Food and Drug Administration, Department of Health and Human Services. 1998. International Conference on Harmonisation: Guidance on statistical principles for clinical trials; availability. Federal Register Vol 63, No 179:49583-49598.

5. Greenberg Report: Organization, review, and administration of cooperative studies. 1988. Control Clin Trials 9:137-148.

6. Ellenberg S, Fleming T, DeMets D. 2002. Data Monitoring Committees in Clinical Trials: A Practical Perspective. John Wiley \& Sons, Ltd., West Sussex, England.

7. Friedman LM, Furberg CD, DeMets DL. 1998. Fundamentals of Clinical Trials. Third Edition, Springer-Verlag, New York.

8. Meinert CL. 1986. Clinical Trials: Design, Conduct, and Analysis. Oxford University Press, New York.

9. Pocock S. 1983. Clinical Trials: A Practical Approach. John Wiley \& Sons, Ltd., West Sussex, England.

10. Jennison C,Turnbull BW. 1999. Group Sequential Methods With Applications to Clinical Trials. Chapman and Hall/CRC, Boca Raton and London.

11. Piantadosi S. 1997. Clinical Trials: A Methodologic Perspective. John Wiley \& Sons, Inc., New York. 


\section{Contributors}

\section{Susan Anderson}

Department of Biostatistics and Medical Informatics, University of Wisconsin, Madison, Wisconsin

Data Monitoring in the Prospective Randomized Milrinone Survival Evaluation: Dealing with an Agonizing Trend

\section{Alex Bajamonde}

Genentech Inc., San Francisco, California

Making Independence Work: Monitoring the Bevacizumab Colorectal Cancer Clinical Trial

\section{Jean-Pierre Boissel}

Clinical Pharmacology Department, Claude Bernard University, Lyon, France Stopping the Randomized Aldactone Evaluation Study Early for Efficacy

\section{Byron W. Brown, Jr.}

Stanford, California

The Nocturnal Oxygen Therapy Trial Data Monitoring Experience:Problem with Reporting Lags

\section{Julie Buring}

Department of Medicine, Brigham and Women's Hospital, Harvard Medical School; Boston, Massachusetts

Stopping the Carotene and Retinol Efficacy Trial: The Viewpoint of the Safety and Endpoint Monitoring Committee

\section{Paul L. Canner}

Maryland Medical Research Institute, Baltimore, Maryland

Breaking New Ground: Data Monitoring in the Coronary Drug Project

\section{Heidi Christ-Schmidt}

Statistics Collaborative, Washington, D.C.

Making Independence Work: Monitoring the Bevacizumab Colorectal Cancer Clinical Trial 


\section{Charles Clark}

Departments of Medicine, Pharmacology and Toxicology, School of Medicine, Indiana University, Bloomington, Indiana

Early Termination of the Diabetes Control and Complications Trial

\section{Patricia Cleary}

The Biostatistics Center, The George Washington University, Rockville, Maryland

Early Termination of the Diabetes Control and Complications Trial

\section{Robert Cody}

Department of Internal Medicine, Division of Cardiology, University of Michigan, Ann Arbor, Michigan

Data Monitoring in the Prospective Randomized Milrinone Survival Evaluation: Dealing with an Agonizing Trend

\section{Theodore Colton}

Department of Epidemiology, Boston University School of Public Health, Boston, Massachusetts

Challenges in Monitoring the Breast Cancer Prevention Trial

\section{Joseph P. Costantino}

Department of Biostatistics, Graduate School of Public Health, University of Pittsburgh, Pittsburgh, Pennsylvania

Challenges in Monitoring the Breast Cancer Prevention Trial

\section{Oscar Crofford}

Department of Medicine, Vanderbilt University, Nashville, Tennessee Early Termination of the Diabetes Control and Complications Trial

\section{Jeffrey A. Cutler}

National Heart, Lung, and Blood Institute, Division of Epidemiology and Clinical Applications, National Institutes of Health, Bethesda, Maryland Data Monitoring in the Antihypertensive and Lipid-Lowering Treatment to Prevent Heart Attack Trial: Early Termination of the Doxazosin Treatment Arm

\section{Barry R. Davis}

The University of Texas Health Science Center at Houston, School of Public Health, Houston, Texas

Data Monitoring in the Antibypertensive and Lipid-Lowering Treatment to Prevent Heart Attack Trial: Early Termination of the Doxazosin Treatment Arm 


\section{David L. DeMets}

Department of Biostatistics and Medical Informatics, University of Wisconsin, Madison, Wisconsin

Data and Safety Monitoring in the Beta-Blocker Heart Attack Trial: Early Experience in Formal Monitoring Methods

Data Monitoring for the Aspirin Component of the Physicians' Health Study: Issues in Early Termination for a Major Secondary Endpoint

The Data Monitoring Experience in the Cardiac Arrbythmia Suppression Trial: The Need To Be Prepared Early

The Nocturnal Oxygen Therapy Trial Data Monitoring Experience:Problem with Reporting Lags

\section{Kenneth Dickstein}

Cardiology Division, Stavanger University Hospital, Stavanger, Norway

Data Monitoring Experience in the Moxonidine Congestive Heart Failure Trial

\section{Fred Ederer}

Bethesda, Maryland

Assessing Possible Late Treatment Effects Early: The Diabetic Retinopathy Study Experience

\section{Susan S. Ellenberg}

University of Pennsylvania School of Medicine, Center for Clinical Epidemiology and Biostatistics, Philadelphia, Pennsylvania

FDA and Clinical Trial Data Monitoring Committees

\section{Frederick Ferris}

Division of Epidemiology and Clinical Research, National Eye Institute, National Institutes of Health, Bethesda, Maryland

Early Termination of the Diabetes Control and Complications Trial

\section{Jan Feyzi}

Department of Biostatistics and Medical Informatics, University of Wisconsin, Madison, Wisconsin

Data Monitoring Experience in the Metoprolol CR/XL Randomized Intervention Trial in Chronic Heart Failure: Potentially High Risk Treatment in High Risk Patients

\section{Dianne M. Finkelstein}

Biostatistics Center, Massachusetts General Hospital; Harvard Medical School, Boston, Massachusetts 
Data Monitoring Experience in the AIDS Clinical Trials Group Study \#981: Conflicting Interim Results

\section{Norman Fost}

Departments of Pediatrics and Medical History and Bioethics, University of Wisconsin, Madison, Wisconsin

Monitoring a Clinical Trial with Waiver of Informed Consent: Diaspirin Cross-Linked Hemoglobin for Emergency Treatment of Post-Traumatic Shock

\section{Gary Francis}

Department of Cardiology, Cleveland Clinic Foundation, Cleveland, Ohio Data Monitoring Experience in the Moxonidine Congestive Heart Failure Trial

\section{Lawrence M. Friedman}

Bethesda, Maryland

Data and Safety Monitoring in the Beta-Blocker Heart Attack Trial: Early Experience in Formal Monitoring Methods

The Data Monitoring Experience in the Cardiac Arrbythmia Suppression Trial: The Need To Be Prepared Early

\section{Curt D. Furberg}

Department of Public Health Sciences, Wake Forest University School of Medicine, Winston-Salem, North Carolina

Stopping the Randomized Aldactone Evaluation Study Early for Efficacy Stopping a Trial for Futility:The Cooperative New Scandinavian Enalapril Survival Study II Trial

Lessons from Warfarin Trials in Atrial Fibrillation: Missing the Window of Opportunity

\section{Saul Genuth}

Division of Clinical and Molecular Endocrinology, Department of Medicine, University Hospitals of Cleveland, Case Western Reserve University, Cleveland, Ohio

Early Termination of the Diabetes Control and Complications Trial

\section{Stephen L. George}

Department of Biostatistics and Bioinformatics, Director, Cancer Center Biostatistics, Duke University Medical Center, Durham, North Carolina Controversies in the Early Reporting of a Clinical Trial in Early Breast Cancer 


\section{Deborah Grady}

Department of Epidemiology and Biostatistics, University of California, San Francisco, California

Consideration of Early Stopping and Other Challenges in Monitoring the Heart and Estrogen/progestin Replacement Study

\section{Mark R. Green}

Department of Hematology/Oncology, Medical University of South Carolina, Charleston, South Carolina

Controversies in the Early Reporting of a Clinical Trial in Early Breast Cancer

\section{Robert J. Hardy}

Division of Biostatistics, The University of Texas Health Sciences Center at Houston, School of Public Health, Houston, Texas

Data and Safety Monitoring in the Beta-Blocker Heart Attack Trial: Early Experience in Formal Monitoring Methods

\section{David Harrington}

Department of Biostatistics and Computational Biology, Dana-Farber Cancer Institute and Department of Biostatistics, Harvard School of Public Health, Boston, Massachusetts

Data Monitoring of a Placebo-Controlled Trial of Daclizumab in Acute Graft-Versus-Host Disease

\section{Robert G. Hart}

Department of Medicine (Neurology), University of Texas Health Science Center, San Antonio, Texas

Early Termination of the Stroke Prevention in Atrial Fibrillation I Trial: Protecting Participant Interests in the Face of Scientific Uncertainties and the Cruel Play of Chance

\section{Charles H. Hennekens}

University of Miami School of Medicine and Florida Atlantic University, Boca Raton, Florida

Data Monitoring for the Aspirin Component of the Physicians' Health Study: Issues in Early Termination for a Major Secondary Endpoint

The Data Monitoring Experience in the Candesartan in Heart Failure Assessment of Reduction in Mortality and Morbidity Program

\section{Eric Holmgren}

Genentech Inc., South San Francisco, California 
xiv Contributors

Making Independence Work: Monitoring the Bevacizumab Colorectal Cancer Clinical Trial

\section{Stephen B. Hulley}

Department of Epidemiology \& Biostatistics, University of California, San Francisco, California

Consideration of Early Stopping and Other Challenges in Monitoring the Heart and Estrogen/progestin Replacement Study

\section{Mark A. Jacobson}

Positive Health Program, Department of Medicine, University of California, San Francisco, California

Data Monitoring Experience in the AIDS Toxoplasmic Encephalitis Study

\section{Desmond G. Julian}

Emeritus Professor of Cardiology, University of Newcastle-upon-Tyne, London, England

Data Monitoring Experience in the Metoprolol CR/XL Randomized Intervention Trial in Chronic Heart Failure: Potentially High Risk Treatment in High Risk Patients

Stopping the Randomized Aldactone Evaluation Study Early for Efficacy The Data Monitoring Experience in the Carvedilol Post-Infarct Survival Control in Left Ventricular Dysfunction Study: Hazards of Changing Primary Outcomes

\section{Richard A. Kronmal}

Department of Biostatistics, University of Washington, Seattle, Washington Early Termination of the Stroke Prevention in Atrial Fibrillation I Trial: Protecting Participant Interests in the Face of Scientific Uncertainties and the Cruel Play of Chance

\section{Henri Kulbertus}

Cardiology Department, Centre Hospitalier Universitaire, Liege, Belgium Stopping the Randomized Aldactone Evaluation Study Early for Efficacy

\section{John M. Lachin}

The Biostatistics Center, The George Washington University, Rockville, Maryland

Early Termination of the Diabetes Control and Complications Trial

\section{Stephanie J. Lee}

Department of Medical Oncology, Dana-Farber Cancer Institute, Boston, Massachusetts

Data Monitoring of a Placebo-Controlled Trial of Daclizumab in Acute Graft-Versus-Host Disease 


\section{Roger J. Lewis}

Department of Emergency Medicine, Harbor-UCLA Medical Center,Torrance, California, UCLA School of Medicine, Los Angeles, California and the Los Angeles Biomedical Research Institute, Torrance, Califormia

Monitoring a Clinical Trial with Waiver of Informed Consent: Diaspirin Cross-Linked Hemoglobin for Emergency Treatment of Post-Traumatic Sbock

\section{Ruth McBride}

Axio Research Corporation, Seattle, Washington

Early Termination of the Stroke Prevention in Atrial Fibrillation I Trial: Protecting Participant Interests in the Face of Scientific Uncertainties and the Cruel Play of Chance

\section{Anthony B. Miller}

Ontario, Canada

Stopping the Carotene and Retinol Efficacy Trial: The Viewpoint of the Safety and Endpoint Monitoring Committee

\section{David Nathan}

Department of Medicine, Harvard University, Boston, Massachusetts

Early Termination of the Diabetes Control and Complications Trial

\section{James D. Neaton}

Division of Biostatistics, School of Public Health, University of Minnesota, Minneapolis, Minnesota

Data Monitoring Experience in the AIDS Toxoplasmic Encephalitis Study

\section{Milton Packer}

Center for Biostatistics and Clinical Science, University of Texas Southwestern Medical Center, Dallas, Texas

Data Monitoring in the Prospective Randomized Milrinone Survival Evaluation: Dealing with an Agonizing Trend

\section{Lesly A. Pearce}

Biostatistical Consultant, Minot, North Dakota

Early Termination of the Stroke Prevention in Atrial Fibrillation I Trial: Protecting Participant Interests in the Face of Scientific Uncertainties and the Cruel Play of Chance

\section{Stuart Pocock}

Medical Statistics Unit, London School of Hygiene and Tropical Medicine, London, United Kingdom 
Stopping the Randomized Aldactone Evaluation Study Early for Efficacy The Data Monitoring Experience in the Candesartan in Heart Failure Assessment of Reduction in Mortality and Morbidity Program

Data Monitoring Experience in the Moxonidine Congestive Heart Failure Trial

Janice Pogue

Department of Medicine and Population Health Research Institute, Hamilton Health Sciences and McMaster University, Hamilton, Ontario, Canada

Data Monitoring in the Heart Outcomes Prevention Evaluation and the Clopidogrel in Unstable Angina to Prevent Recurrent Ischemic Events Trials: Avoiding Important Information Loss

Data Monitoring in the Randomized Evaluation of Strategies for Left Ventricular Dysfunction Pilot Study: When Reasonable People Disagree

\section{Carol K. Redmond}

Department of Biostatistics, Graduate School of Public Health, University of Pittsburgh, Pittsburgh, Pennsylvania

Challenges in Monitoring the Breast Cancer Prevention Trial

\section{David Sackett}

Trout Research and Education Centre at Irish Lake, Markdale, Ontario, Canada Data Monitoring in the Heart Outcomes Prevention Evaluation and the Clopidogrel in Unstable Angina to Prevent Recurrent Ischemic Events Trials: Avoiding Important Information Loss

\section{Richard Schwarz}

CV Ventures, LLC, Blue Bell, Pennsylvania

Data Monitoring in the Prospective Randomized Milrinone Survival Evaluation: Dealing with an Agonizing Trend

\section{Carolyn Siebert}

Scotland, Maryland

Early Termination of the Diabetes Control and Complications Trial

\section{Jay P. Siegel}

Centocor Research and Development, Inc., Malvern, Pennsylvania FDA and Clinical Trial Data Monitoring Committees

\section{Steven Snapinn}

Amgen Inc., Thousand Oaks, California

Stopping a Trial for Futility:The Cooperative New Scandinavian Enalapril Survival Study II 


\section{Charles H. Tegeler}

Department of Neurology, Wake Forest University School of Medicine, Winston-Salem, North Carolina

Lessons from Warfarin Trials in Atrial Fibrillation: Missing the Window of Opportunity

\section{Eric Vittinghoff}

Department of Epidemiology and Biostatistics, University of California, San Francisco, California

Consideration of Early Stopping and Other Challenges in Monitoring the Heart and Estrogen/progestin Replacement Study

\section{Duolao Wang}

Medical Statistics Unit, London School of Hygiene and Tropical Medicine, London, United Kingdom

The Data Monitoring Experience in the Candesartan in Heart Failure Assessment of Reduction in Mortality and Morbidity Program

\section{Hans Wedel}

Epidemiology and Biostatistics, Nordic School of Public Health, Göteborg, Sweden

Data Monitoring Experience in the Metoprolol CR/XL Randomized Intervention Trial in Chronic Heart Failure: Potentially High Risk Treatment in High Risk Patients

\section{Deborah N. Wentworth}

Division of Biostatistics, School of Public Health, University of Minnesota, Minneapolis, Minnesota

Data Monitoring Experience in the AIDS Toxoplasmic Encephalitis Study

\section{Richard J. Whitley}

Pediatrics, Microbiology, Medicine and Neurosurgery, University of Alabama at Birmingham, Alabama

Clinical Trials of Herpes Simplex Encephalitis: The Role of the Data Monitoring Committee

\section{John Wikstrand}

Wallenberg Laboratory for Cardiovascular Research, Sahlgrenska University Hospital, Göteborg; and Clinical Science, Astra Zeneca R\&D, Mölndal, Sweden

Data Monitoring Experience in the Metoprolol CR/XL Randomized Intervention Trial in Chronic Heart Failure: Potentially High Risk Treatment in High Risk Patients 


\section{Lars Wilhelmsen}

Section of Cardiology, The Cardiovascular Institute, Göteborg University, Sweden

The Data Monitoring Experience in the Candesartan in Heart Failure Assessment of Reduction in Mortality and Morbidity Program

Data Monitoring Experience in the Moxonidine Congestive Heart Failure Trial

\section{George W. Williams}

Amgen Inc., Thousand Oaks, California

The Nocturnal Oxygen Therapy Trial Data Monitoring Experience:Problem with Reporting Lags

\section{O. Dale Williams}

Division of Preventive Medicine, Department of Medicine, University of Alabama, Birmingham, Alabama

Stopping the Carotene and Retinol Efficacy Trial: The Viewpoint of the Safety and Endpoint Monitoring Committee

Consideration of Early Stopping and Other Challenges in Monitoring the Heart and Estrogen/progestin Replacement Study

\section{Janet Wittes}

Statistics Collaborative, Washington, D.C.

Stopping the Randomized Aldactone Evaluation Study Early for Efficacy

Data Monitoring Experience in the Moxonidine Congestive Heart Failure Trial

Making Independence Work: Monitoring the Bevacizumab Colorectal Cancer Clinical Trial

\section{D.G. Wyse}

Libin Cardiovascular Institute of Alberta, Calgary, Alberta, Canada

Data Monitoring in the Heart Outcomes Prevention Evaluation and the Clopidogrel in Unstable Angina to Prevent Recurrent Ischemic Events Trials: Avoiding Important Information Loss

\section{Salim Yusuf}

Department of Medicine and Population Health Research Institute, Hamilton Health Sciences and McMaster University, Hamilton, Ontario, Canada Data Monitoring in the Heart Outcomes Prevention Evaluation and the Clopidogrel in Unstable Angina to Prevent Recurrent Ischemic Events Trials: Avoiding Important Information Loss 
Data Monitoring in the Randomized Evaluation of Strategies for Left Ventricular Dysfunction Pilot Study:When Reasonable People Disagree

\section{David Zahrieh}

Department of Biostatistics and Computational Biology, Dana-Farber Cancer Institute, Boston, Massachusetts

Data Monitoring of a Placebo-Controlled Trial of Daclizumab in Acute Graft-Versus-Host Disease 


\section{Contents}

Preface

Contributors $\quad$ ix

Section 1: Introduction/Overview

1 Monitoring Committees: Why and How

David L. DeMets

Curt D. Furberg

Lawrence M. Friedman

$2 \quad$ Lessons Learned

David L. DeMets

Curt D. Furberg

Lawrence M. Friedman

3 FDA and Clinical Trial Data Monitoring Committees

Susan S. Ellenberg

Jay P. Siegel

\section{Section 2: General Benefit}

Introduction to Case Studies Showing

Benefit From the Intervention

David L. DeMets

Curt D. Furberg

Lawrence M. Friedman

Case 1 Assessing Possible Late Treatment Effects

Early: The Diabetic Retinopathy Study

Experience

Fred Ederer

Case 2 Data and Safety Monitoring in the Beta-

Blocker Heart Attack Trial: Early Experience

in Formal Monitoring Methods

Lawrence M. Friedman

David L. DeMets

Robert Hardy 
xxii Contents

Case 3 Data Monitoring for the Aspirin Component of the Physicians' Health Study: Issues in Early Termination for a Major Secondary Endpoint

David L. DeMets

Charles H. Hennekens

Case 4 Early Termination of the Stroke Prevention in Atrial Fibrillation I Trial: Protecting

Participant Interests in the Face of Scientific Uncertainties and the Cruel Play of Chance

Robert G. Hart

Lesly A. Pearce

Ruth McBride

Richard A. Kronmal

Case 5 Early Termination of the Diabetes Control and Complications Trial

Jobn M. Lachin

Patricia Cleary

Oscar Crofford

Saul Genuth

David Nathan

Charles Clark

Frederick Ferris

Carolyn Siebert

for the DCCT Research Group

Case 6 Data Monitoring in the AIDS Clinical Trials

Group Study \#981: Conflicting Interim Results

Dianne M. Finkelstein

Case 7 Challenges in Monitoring the Breast Cancer

Prevention Trial

Carol K. Redmond

Joseph P. Costantino

Theodore Colton

Case 8 Data Monitoring Experience in the Metoprolol

$\mathrm{CR} / \mathrm{XL}$ Randomized Intervention Trial in

Chronic Heart Failure: Potentially High-Risk

Treatment in High-Risk Patients

Jan Feyzi

Desmond Julian

Jobn Wikstrand

Hans Wedel 
Case 9 Stopping the Randomized Aldactone

Evaluation Study Early for Efficacy

148

Janet Wittes

Jean-Pierre Boissel

Curt D. Furberg

Desmond Julian

Henri Kulbertus

Stuart Pocock

Case 10 Data Monitoring in the Heart Outcomes

Prevention Evaluation and the Clopidogrel

in Unstable Angina to Prevent Recurrent

Ischemic Events Trials: Avoiding Important

Information Loss

158

Janice Pogue

David Sackett

DG Wyse

Salim Yusuf

Case 11 The Data Monitoring Experience in the

Candesartan in Heart Failure Assessment of

Reduction in Mortality and Morbidity Program

166

Stuart Pocock

Duolao Wang

Lars Wilbelmsen

Charles H. Hennekens

\section{Section 3: General Harm}

Introduction to Case Studies Showing

Harmful Effects of the Intervention

David L. DeMets

Curt D. Furberg

Lawrence M. Friedman

Case 12 Breaking New Ground: Data Monitoring in the Coronary Drug Project

Paul L. Canner

Case 13 The Data Monitoring Experience in the Cardiac Arrhythmia Suppression Trial: The Need To Be Prepared Early

David L. DeMets

Lawrence M. Friedman 
xxiv Contents

Case 14 Data Monitoring in the Prospective

Randomized Milrinone Survival Evaluation:

Dealing with an Agonizing Trend

Susan Anderson

Robert Cody

Milton Packer

Richard Schwarz

Case 15 Stopping the Carotene and Retinol Efficacy

Trial: The Viewpoint of the Safety and

Endpoint Monitoring Committee

Antbony B. Miller

Julie Buring

O. Dale Williams

Case 16 Monitoring a Clinical Trial With Waiver of Informed Consent: Diaspirin Cross-Linked Hemoglobin for Emergency Treatment of Post-Traumatic Shock

Roger J. Lewis

Norman Fost

Case 17 Consideration of Early Stopping and Other Challenges in Monitoring the Heart and Estrogen/Progestin Replacement Study

Stephen B. Hulley

Deborab Grady

Eric Vittinghoff

O. Dale Williams

Case 18 Data Monitoring in the Antihypertensive and Lipid-Lowering Treatment to Prevent Heart Attack Trial: Early Termination of the Doxazosin Treatment Arm

Barry R. Davis

Jeffrey A. Cutler

Case 19 Data Monitoring Experience in the Moxonidine

Congestive Heart Failure Trial

Stuart Pocock

Lars Wilbelmsen

Kenneth Dickstein

Gary Francis

Janet Wittes 
Case 20 Data Monitoring of a Placebo-Controlled

Trial of Daclizumab in Acute Graft-

Versus-Host Disease

David Zabrieb

Stephanie J. Lee

David Harrington

Section 4: Special Issues

Introduction to Case Studies With Special Issues

David L. DeMets

Curt D. Furberg

Lawrence M. Friedman

Case 21 Clinical Trials of Herpes Simplex Encephalitis:

The Role of the Data Monitoring Committee

Richard J. Whitley

Case 22 The Nocturnal Oxygen Therapy Trial Data

Monitoring Experience: Problem With

Reporting Lags

292

David L. DeMets

George W. Williams

Byron W. Brown, Jr.

Case 23 Stopping a Trial for Futility: The Cooperative

New Scandinavian Enalapril Survival Study II

Steven Snapinn

Curt D. Furberg

Case 24 Lessons From Warfarin Trials in Atrial

Fibrillation: Missing the Window of

Opportunity

Charles H. Tegeler

Curt D. Furberg

Case 25 Data Monitoring Experience in the AIDS

Toxoplasmic Encephalits Study

James D. Neaton

Deborab N. Wentworth

Mark A.Jacobson 
XXvi Contents

Case 26 Data Monitoring in the Randomized Evaluation of Strategies for Left Ventricular Dysfunction Pilot Study: When Reasonable People Disagree Janice Pogue Salim Yusuf

Case 27 The Data Monitoring Experience in the Carvedilol Post-Infarct Survival Control in Left Ventricular Dysfunction Study: Hazards of Changing Primary Outcomes Desmond Julian

Case 28 Controversies in the Early Reporting of a Clinical Trial in Early Breast Cancer

Stephen L. George

Mark R. Green

Case 29 Making Independence Work: Monitoring the Bevacizumab Colorectal Cancer Clinical Trial Janet Wittes

Eric Holmgren

Heidi Christ-Schmidt

Alex Bajamonde

Appendix 1 Data Monitoring Committee Members

Appendix 2 Case Study Acronym Key (Title) 
SECTION 1

Introduction/Overview 